\title{
COMPARISON OF POST-DURAL PUNCTURE HEADACHE IN SPINAL ANAESTHESIA USING 25-GAUGE VERSUS 29-GAUGE SPINAL NEEDLE
}

\author{
Sanjeev Kumar ${ }^{1}$, Ashutosh Kumar ${ }^{2}$
}

${ }_{1}^{1}$ Associate Professor, Department of Anaesthesiology, MGM Medical College and Hospital, Jamshedpur, Jharkhand, India.

2Junior Resident, Department of Anaesthesiology, MGM Medical College and Hospital, Jamshedpur, Jharkhand, India.

\begin{abstract}
BACKGROUND
Incidence of post-dural puncture headache varies from $0 \%$ to $16 \%$ depending upon the gauge of spinal needle used. A nonrandomised controlled trial study was conducted to compare the incidence of post-dural headache in spinal anaesthesia using 25gauge and 29-gauge spinal needle. 100 patients between 18 and 40 years age belonging to ASA group I and II of pregnant female patient were taken to receive a spinal anaesthesia with 25-gauge/ 29-gauge spinal needle for LSCS operation. The incidence, type, severity, day of onset and site of post-dural punctured headache was recorded for first 4 operative days and data obtained was analysed for any significant difference among the two groups. Incidence of post-dural spinal headache was significantly high in patients on whom 25-gauge spinal needle was used as compared to those with 29-gauge spinal needle.
\end{abstract}

ABSTRACT

\section{MATERIALS AND METHODS}

The non-randomised controlled trial study was conducted on a total of 100 pregnant patients belonging to ASA Group I and II with age group ranging from 18 to 40 years after taking prior consent from the patient and approval from Hospital Committee.

\section{RESULTS}

One hundred patients were subjected to LSCS operation. Patients' details and volume of drugs used are given in Table 1. Post-dural puncture headache occurred in four patients (8\%) of Group I. Two patients' headache lasted for two days, while in other two patients headache lasted for 1 day.

\section{CONCLUSION}

This implies that 29-gauge needle is difficult to use. We also concluded that weight and age are not the risk factors for PDPH.

\section{KEY WORDS}

Anaesthesia: Intrathecal Block Complication: Post-Dural Puncture Headache, Spinal Needle: 25-Gauge and 29-Gauge Spinal Needle. HOW TO CITE THIS ARTICLE: Kumar S, Kumar A. Comparison of post-dural puncture headache in spinal anaesthesia using 25gauge versus 29-gauge spinal needle. J. Evolution Med. Dent. Sci. 2018;7(36):4035-4037, DOI: 10.14260/jemds/2018/901

\section{BACKGROUND}

Post-Dural Puncture Headache ${ }^{[1],[2]}$ was mentioned in research conducted by August Bier following subarachnoid injection of cocaine in year 1889. High incidence of PDPH has been reported in young patients even when small-bore needles like 25-gauge were used. The introduction of use of 29-gauge spinal needle represents a promising attempt to reduce the incidence of PDPH. Neuraxial anaesthesia have several advantages namely decreased risk of failed intubation, aspiration of gastric content, avoiding the use of depressant agent, ability of mother to remain awake and reduced blood loss. We decided to compare 25- and 29-gauge needles in two groups of pregnant patients with regards to the incidence of post-dural puncture headache and to evaluate the failure rate. Spinal anaesthesia is recommended as first choice in pregnant women of ASA grade I and II going to be LSCS operation. Spinal anaesthesia is safe for both mother as well as foetus.

'Financial or Other Competing Interest': None.

Submission 25-07-2018, Peer Review 18-08-2018,

Acceptance 24-08-2018, Published 03-09-2018.

Corresponding Author:

Dr. Sanjeev Kumar,

Siddheshwar Smriti Kunj,

P. No. 495, Road No. 5,

Hari Om Nagar,

Adityapur-I, Jamshedpur-831013,

Jharkhand, India.

E-mail: kumar.sanjeev9248@gmail.com

DOI: $10.14260 /$ jemds $/ 2018 / 901$

\section{(c) $($ ) $९$}

But this technique has few complications which includes post-dural puncture headache, back ache, cranial nerve palsy, meningitis, hypotension, bradycardia and even cardiac arrest.[3]

Under all aseptic precautions, lumbar puncture was performed in sitting position at L3-L4 or L4-L5 intervertebral space. A 23-gauge hypodermic needle was used as an introducer for 29-gauge spinal needle. Correct positioning was confirmed by appearance of gauge needle and in case of 29 gauge needle by aspiration with syringe attached to the needle. Spinal anaesthesia was performed with hyperbaric $0.5 \%$ bupivacaine. Post-operatively, patients were made ambulatory as soon as possible. All patients were followed up for first four post-operative days. The incidence type, severity, duration, day of onset and site of headache were recorded. Post-dural puncture headache was aggravated by erect or sitting position relieved by lying flat. Headache accompanied by dizziness, vomiting, visual disturbance and neck rigidity. Post-dural puncture headache is relieved by bed rest, analgesic, plenty of water and intravenous fluid.

\section{MATERIALS AND METHODS}

The non-randomised controlled trial study was conducted on a total of 100 pregnant patients belonging to ASA Group I and II with age group ranging from 18 to 40 years after taking prior consent from the patient and approval from hospital committee. The first 50 persons with each group of drug gauge spinal needle used for dural puncture were taken up and the 
sample size taken for the study for convenience. Gauge spinal needle was used for dural puncture given was based on availability at various times. Convenient sampling method was used, as first fifty consented persons in each group were taken up for the study. 50 patients in each group undergoing gauge spinal needle was used for dural puncture. To compare the incidence of post-dural headache in spinal anaesthesia using 25-gauge and 29-gauge spinal needle. 100 patients between 18 and 40 years age belonging to ASA group I and II of pregnant female patients were taken to receive a spinal anaesthesia with 25-gauge/ 29-gauge spinal needle for LSCS operation. The incidence, type, severity, day of onset and site of post-dural punctured headache was recorded for first 4 operative days and data obtained was analysed for any significant difference among the two groups. Incidence of postdural spinal headache was significantly high in patients on whom 25-gauge spinal needle was used as compared to those with 29-gauge spinal needle. Study by convenient sampling technique. Since the duration of the study was 3 months, sample size was taken as convenience.

\section{Statistics}

The data were entered into a proforma and statistical analysis was conducted by using SPSS version 14.0 software. Chisquare test was used to compare the difference in percentage of incidence of VAP between two groups. Age, APACHE-II Score, duration of mechanical ventilation and duration of ICU stay was expressed as mean with standard deviation or median with range. The comparison of these variables between the groups were carried out by using student $t$-test based on distribution of data. A p $<0.05$ was considered statistically significant.

\section{RESULTS}

One hundred patients were subjected to LSCS operation. Patient's details and volume of drugs used are given in Table 1.

\begin{tabular}{|c|c|c|}
\hline & $\begin{array}{c}\text { Group I } \\
\text { (25-Gauge) } \\
\text { N1= 50 }\end{array}$ & $\begin{array}{c}\text { Group II } \\
\text { (29-Gauge) } \\
\text { N2= 50 }\end{array}$ \\
\hline $\begin{array}{c}\text { Mean age } \\
\text { (in years } \pm \text { SD) }\end{array}$ & $32.5 \pm 6.5$ & $31.05 \pm 8.5$ \\
\hline Mean weight (kg \pm SD) & $54.75 \pm 7.5$ & $56.55 \pm 6.5$ \\
\hline $\begin{array}{c}\text { Mean volume } \\
(\mathrm{mL}) \text { bupivacaine } \\
(0.5 \% \text { hyperbaric) (mL } \pm \\
\text { SD) }\end{array}$ & $3.20 \pm 0.22$ & $3.25 \pm 0.22$ \\
\hline $\begin{array}{c}\text { Table 1. Patient details (Age and Weight) and } \\
\text { Volume of Drug }\end{array}$ \\
\hline \multicolumn{2}{|c}{} \\
\hline
\end{tabular}

$\mathrm{p}<0.05$.

Post-dural puncture headache occurred in four patients (8\%) of Group I. Two patient's headache lasted for two days, while in other two patient's headache lasted for 1 day. Three patients were reported having nausea, vomiting and dizziness. In Group II, none of the patients reported for post spinal headache even after multiple attempts. Incidence of post-dural puncture headache and number of attempts for dural puncture is given in Table 2 .

\begin{tabular}{|c|c|c|}
\hline & $\begin{array}{c}\text { Group I } \\
\text { (25-Gauge) } \\
\text { N1= 50 }\end{array}$ & $\begin{array}{c}\text { Group II } \\
\text { (29-Gauge) } \\
\text { N2= 50 }\end{array}$ \\
\hline PDPH & 4 & 0 \\
\hline Number of attempts 1 & 48 & 44 \\
\hline 2 & 2 & 4 \\
\hline 3 & 0 & 2 \\
\hline
\end{tabular}

Table 2. Incidence of Post-Dural Puncture Headache and number of attempts for Dural Puncture

$\mathrm{p}<0.05$.

\section{Limitation of the Study}

Due to short duration of the study, convenience sampling technique was followed. Thus, sampling size was also calculated by convenience. The results of the study cannot be generalised due to the potential bias resulting from the sampling technique and sample size estimation.

\section{DISCUSSION}

Post-dural puncture headache occurs due to leakage of CSF in dural space. The incidence, severity and duration of headache is directly related to the size of hole in dura made by the spinal needle.[4] CSF losses continues as long as the dura hole exists. There is decrease in subarachnoid space volume and pressure, which results in descent of the brain onto pain sensitive structure leading to postural headache. Other complications like nausea, vomiting and dizziness may occur.

Reported incidence of PDPH with 25-gauge spinal needle was $7.4 \%,{ }^{[2]} 4.3 \%{ }^{[5]}$ and $8.7 \%,{ }^{[6]}$ while with 29 -gauge needle it was $0 \%,{ }^{[7]} 2.12 \%{ }^{[8]}$ and $1.2 \% .^{[9]}$ Geurts et al[1] showed an incidence of $25 \%$ with 25 -gauge needle and $0 \%$ with 29 -gauge needle.

In this research, 100 pregnant female patients with age group ranging from 18 years to 40 years, with no prior headache condition, it was found that PDPH incidence occurred in $8 \%$ of the patients treated with 25 -gauge needle and $0 \%$ of the patients treated with 29 -gauge needle.

In Group II (29-gauge) two patients required three or more attempts for dural puncture, while four patients required two attempts.

\section{CONCLUSION}

This implies that 29-gauge needle is difficult to use. We also concluded that weight and age are not the risk factors for PDPH. Our conclusion was that 29-gauge needle is technically difficult to use, but carries very low risk of PDPH.

\section{REFERENCES}

[1] Geurts JW, Haanschoten MC, Van Wijk RM, et al. Post dural puncture headache in young patients. A comparative study between the use of $0.52 \mathrm{~mm}(25-$ gauge) and $0.33 \mathrm{~mm}$ (29-gauge) spinal needles. Acta Anaethesiol Scand 1990;34(5):350-3.

[2] Tarkkila P, Huhtata J, Salminen U. Difficulties in spinal needle use. Insertion characteristics and failure rates associated with 25-, 27- and 29- gauge Quinkle-type spinal needles. Anaesthesia 1994;49(8):723-5.

[3] Caplan RA, Ward RJ, Posner K, et al. Unexpected cardiac arrest during spinal anaesthesia: a closed claims analysis of predisposing factors. Anaethesiology 1988;68(1):5-11. 


\section{Jemds.com}

[4] Tourtellotte WW, Henderson WG, Tucker RP, et al. A randomized, double-blind clinical trial comparing 22 versus 26 gauge needle in the production of postlumbar puncture syndrome in normal individuals. Headache 1972;12(2):73-8.

[5] Eriksson Al, Hallen B, Lagerkranser M, et al. Whitacre or Quincke needles - does it really matter. Acta Anaethesisol Scand Suppl 1998;113:17-20.

[6] Vallejo MC, Mendell GL, Sabo DP, et al. Postdural puncture headache: a randomized comparison of five spinal needles in obstetric patients. Anaesthesia Analag 2000;91(4):916-20.

\section{Original Research Article}

[7] Carrie LES, Collins PD. 29 gauge spinal needle. Br J Anaeth 1991;66:145-6.

[8] Dahl JB, Scultz P, Anker-Moller E, et al. Spinal anaesthesia in young patients using 29 gauge needle: technical considerations and an evaluation of postoperative complaints compared with general anaesthesia. Br J Anaesth 1990;64(2):178-82.

[9] Dittmann H, Schaefer HG, Renkl F, et al. Spinal anaesthesia with 29 gauge Quincke point needles and post dural puncture headache in 2,378 patients. Acta Anesthesiol Scand 1994;38(7):691-3. 